\title{
UN VIAJE A LA IRONÍA Fausto Pretelin*
}

\section{La ironía es el lenguaje del pensa-} miento inquieto. Arrinconado por la cotidianidad de la simpleza y amenazado por la pérdida de gramaje del pensamiento, el irónico escapa de la atmósfera mimética gracias al diálogo consigo mismo por medio de una tercera persona. Esa sencilla experiencia, olvidada o despreciada por muchos, es la encargada de nutrir de alegría al personaje irónico que, al hacerlo, logra desdoblarse o escapar del original (el cotidiano). Dos personajes en uno. El irónico y el cotidiano. La ficción alumbra al irónico. El otro, el cotidiano, se abriga con la penumbra perenne. El irónico recorre el camino de la reflexión a altas velocidades. El otro, arranca en tercera velocidad. El irónico reacciona y responde. El cotidiano, responde pero no reacciona. El irónico entiende que la incomprensión es un callejón sin salidas. La única opción es recurrir al esteticismo del pensamiento. Lo hace y escapa. Pero todo diálogo, mediante un tercero, requiere de inteligencia.

Julián Meza se regodea desde la ironía. En ella dibuja la cartografía que mejor describe a su personalidad: los bestiarios. Julián dialoga consigo mismo a través de terceros. Éstos, casi siempre, son políticos.

En Bestiario de la modernidad mexicana y diccionario posmoderno, Julián reviste la palabra Estadista con signos de interrogación que, al quitárselos queda la siguiente definición: ¡Los de antaño! A la estafa

* Periodista y profesor. 
la define como fraude perpetrado desde los bajos fondos de la zahúrda presidencial. O qué decir de Pocilga, definida por Julián como la residencia presidencial. Al secretario de Estado, Julián lo define de la siguiente manera: Gato de angora.

No es casualidad que la política se convierta en el eje toral de los bestiarios. Una actividad, tan indolente con la sociedad, que su lenguaje es inútil frente al aterciopelado diálogo.

En México las palabras, muchas de ellas, no dicen lo que creemos que significan. Su fonética es ociosa. No reflejan la naturaleza de donde nacieron. Es, la retórica, la prisión del pensamiento. Por eso, Julián la somete a revisión. Como médico de los significados, palabra por palabra, las ingresa al quirófano de la conciencia. Las examina. Trabaja con ellas. Les modifica su rostro, su sonido. Las reinventa. Posteriormente, las libera. Julián acaba con la retórica gracias a su diálogo interno a través de un tercero.

Para Meza, quizá, el peor invento de nuestro mundo sean los pasaportes, documentos encargados de desordenar la cohabitación del ser humano. La libertad se desintegra a través de cuestionarios. República de la Burocracia. En defensa del documento, los políticos radicalizan su discurso. Instruyen. Ordenan a la población en "islas" para desintegrarlos; se comunican con ellos a través de Oficios y Tarjetas burocráticas. Fabrican los desincentivos más atractivos para domesticarlos. De esta manera, se crean una serie de "iconos nacionalistas". En ellos se mimetiza la falsa unión. Supongamos que hablamos del grito del mariachi o, si se prefiere, del Grito. Entendemos que a Julián le enfada la caricatura de una construcción permanente de una nación. No es necesario ser un espeleólogo en la cartografía de Julián para encontrar sus motivos. Julián es un viajero permanente. Desde la ingravidez del pensamiento despega a sitios recónditos. Generalmente al Mediterráneo. Pero también a sus ciudades como París. Y es que uno reinventa las atmósferas a su conveniencia y placer. La imaginación penetra en el corazón de las atmósferas inspiradoras. Estamos en la ficción. En sus terrenos literarios no se aceptan pasaportes. Desde ahí, Julián expulsa al mexicano hiper nacionalista, que se presenta eufórico con pasaporte bajo el brazo y una bandera cubriéndole la cabeza. 
Uno de los aventurados viajes de Julián se llama Estudios. En su primer número, octubre de 1984, Julián nos reveló los nombres de sus compañeros de viaje: Artaud, Rabelais, Broch, Proust, Joyce, Musil, Kafka, Kundera y Shakespeare. Sin fronteras, pasaportes y burócratas. Imposible pensar en nacionalidades cuando el eterno viaje es literario. En ese primer número de Estudios, Julián escribe: "Es evidente que la literatura no pertenece, para nada, al dominio de la realidad y de la racionalidad donde se cocinan la física, la química, la sociología, la economía; pero no carece de su propia realidad. Contra la costumbre de separar radicalmente la literatura de la realidad, se puede mirar la literatura de otra manera: como una realidad que cuenta con su propio terreno y, además, con la posibilidad de relacionarse con otros territorios".

Una tarde, coincidí con Julián Meza, en el auditorio del ITAM, en una tertulia sobre nacionalismo. El primer comentario de Julián versó sobre su incomprensión por el dictado gastronómico nacionalista que tanto agobia y fascina al mexicano. Se preguntaba Julián:

¿Por qué me tiene que gustar más el taco que la baguette? ¿Por qué debo mostrar preferencia por el tequila sobre el vino? Sencillos cuestionamientos sobre complejos rasgos alegóricos construidos, tal vez, en películas de Pedro Infante. Regreso a su bestiario de la modernidad mexicana para rescatar algunas de sus definiciones.

El panal de las estrellas: Escenario de la telenovela nacional. Ver Telenovela nacional. Y, a manera de cartelera, Julián la describe de la siguiente manera:

Telenovela nacional (1): El vuelo de Dumbo.

Telenovela nacional (2): Muchachitas sacadólares.

Telenovela nacional (3): El premio gordo del enano.

Telenovela nacional (4): El tesoro de Tilín.

Telenovela nacional (5): La pesca de los Sardinas.

Telenovela nacional (6): Imperio de pacotilla.

Telenovela nacional (7): Carrusel de infamias.

Telenovela nacional (8): Sardinas frescas en Almoloya. 
La indiferencia por el conocimiento y la fe ciega por los nacionalismos han sido la eterna preocupación de Julián. El gobierno de la televisión, el odio por la imaginación, el pantano de los libros, la escritura dictada, es decir, anémica, el nulo entusiasmo de la demografía por la lectura de los clásicos, el urbanismo que huye del esteticismo, el París sin sentimientos, es decir, turístico, la Barcelona tomada por los neofranquistas y el circo de Berlusconi son, entre muchos otros, los componentes de su laberinto.

Julián concibe a la crítica como una fiesta. Se columpia en el espectro que cubren los ángulos irónico y lúdico. En el gimnasio del pensamiento, los juegos facilitan la ampliación de la musculatura crítica. Julián es un hombre fuerte. No es de sorprenderse que la academia sea el más atractivo de los gimnasios del pensamiento.

La academia requiere de pasión por la cultura pero, sobre todo, por la crítica. El profesor Meza les transfiere a sus alumnos el gusto por ella. Muchos de ellos, no satisfechos por la duración de la clase y la finitud del semestre, lo buscan. Inquietos por viajar con él, piensan, dialogan y escriben. Algunos de sus discípulos se han convertido en poetas, otros se han aventurado en la fabricación de historias noveladas $\mathrm{y}$, finalmente, algunos otros han elegido al ensayo como compañero de viaje.

Felicidades a Julián Meza por su braceo inagotable que ha llevado a Estudios al número 100. 